Please note this text is the author's manuscript. It is not the final published version of the paper.

Orrego-Carmona, David (2016): A reception study on non-professional subtitling. Do audiences notice any difference? In Across Languages and Cultures 17 (2), pp. 163-181. DOI: http://dx.doi.org/10.1556/084.2016.17.2.2.

\title{
A reception study on non-professional subtitling: do audiences notice any difference?
}

\author{
David Orrego-Carmona
}

\author{
University of the Free State \\ 205 Nelson Mandela Drive, P.O. Box 339, Bloemfontein 9300 (South Africa) \\ Phone: +27(0) 514019621, fax: +27(0) 514019959 \\ E-mail: OrregoCarmonaJD@ufs.ac.za
}

\begin{abstract}
The audience's reluctance to wait for the international release of audiovisual products, coupled with the easy access to audiovisual material and subtitling tools on the Internet, has triggered an increase in the production and use of non-professional subtitling. However, up to now, we know little of how people receive the subtitles and how much they understand when watching products with non-professional subtitles. This paper presents the results of a study that explores the audience reception of subtitled TV series using professional and non-professional subtitling. Fifty-two participants were shown three excerpts from The Big Bang Theory with three subtitle versions: the professional version extracted from the Spanish DVD and two non-professional versions produced by two different nonprofessional subtitling communities. Data were collected through questionnaires, eye-tracking and interviews. The results show that non-professional subtitles do not necessarily affect the audience reception negatively. Further, both eye-tracking and self-reported data yielded interesting insights into audience's reception. Based on the findings, it is possible to say that there are non-professional translations that are as good as their professional counterparts.
\end{abstract}

Key words: reception, subtitling, non-professional subtitling, audience, eye tracking 


\section{Introduction}

Traditionally people had to wait for the official international release of audiovisual content; the international distribution of content was delayed due to distribution and scheduling conditions. However, technological tools and, above all, the Internet have made it easy for people to take on the distribution of the content they like. Thanks to this, people around the world have the possibility to access audiovisual content online without being subject to international release schedules. These prosumers, active consumers who have taken on some of the producers' tasks (Tapscott \& Williams, 2006), not only participate in the distribution of the content as it is, but adopt the role of translators and help others who do not know the source language. For the content to arrive at a wider audience, people have organized themselves in groups that create subtitles in different languages.

In recent years, Translation Studies has started to pay more attention to non-professional subtitling. The growing number of studies in this area is actually delineating a path that could produce outcomes leading to convergence between professional and non-professional subtitling: by discovering what non-professionals are doing, we could then learn how people conceive of translation and see how their conceptions support or challenge what we know about translation and the translation profession. In order to enlarge our knowledge of nonprofessional subtitling, this paper sets out to explore how people's reception is affected by the type of subtitles they watch.

\section{Professional and non-professional subtitling}

The first distinction that should be explained is what I mean by non-professional translation. One way of reaching a practical definition of non-professionalism is by opposing it to professionalism. In line with critical sociology, the definition of a profession is constructed in terms of exclusion: a professional is someone who can provide a service that the buyers of the service cannot do themselves (Pym, 2012). Clients pay translators to do their job and, as they do not necessarily have the knowledge or expertise to revise the translation, they trust the work provided by the translators. Professional translators have different forms of being recognized as such: some have the expertise that allows them to call themselves translators, others have completed academic training that grants them a professional degree in translation, and yet others become members of translator associations that give them the prestige to perform as translators as well as the recognition of peers (Pym, 2014). Training, expertise, association or a combination of these criteria can work as a signal of trustworthiness and 
could be used to distinguish between professional and non-professional translators. In reality, all these signals cohabitate in the translation market. Nevertheless, from a research perspective, setting the boundaries between professional and non-professional groups of translators and their products, using the criteria described above is almost an impossible task. Some non-professional translators have already been translating for a considerable amount of time, which can count as experience. Scholars have argued that non-professional translators actually improve as translators over time (Barra, 2009; Dwyer, 2012; Massidda, 2012) and also that expertise does not necessarily equal professionalism (Jääskeläinen, 2010). Additionally, there is nothing keeping translators who have graduated from training programs from collaborating in non-professional initiatives.

Thus, the concept of professional translation is complex and none of the characteristics introduced above serve to establish a straight-forward boundary between professionals and non-professionals. In this paper, I rely on monetary reward as the characteristic to differentiate between the two groups. Professional translators are not only trusted with a translation but also paid for the task they perform. I subscribe to this professional / nonprofessional opposition because I believe it is the one that best describes the current state of affairs: professional translators are hired and paid as translators as opposed to outsiders who do not receive payment for their translations. It is true that other rewards might be obtained in non-professional translation settings (Fernández Costales, 2013; O’Hagan, 2011), however, when a translation is not paid for, the conditions under which it is produced, according to my definition, make it non-professional.

\subsection{Professional-amateur (pro-am) subtitling}

The lack of payment not only distinguishes between professional and non-professional, it stands out as an essential feature that binds together all non-professional translation activities. Since the beginning of this century, non-professional translation has expanded and touched on many different types of translation, ranging from self-organized groups of volunteers who decide on the content they translate and manage the entire translation process to companydriven initiatives, crowdsourcing (Fernández Costales, 2012). This comes as a result of the democratization of technology and the empowerment of users: people realize that technological tools enhance their efforts and can multiply the impact of their collective work. In the study I am presenting, I included one type of non-professional subtitling only: professional-amateur (pro-am) subtitling (Leadbeater \& Miller, 2004). Pro-am subtitling is the 
type of non-professional subtitling that tries to imitate professional subtitling. The goal of these groups' members is to produce subtitles that are comparable to the subtitles they see at the cinema or on television, while still taking into account the specific needs of their target audience. The communities normally organize themselves as online discussion forums, and agree on certain types of translation guidelines. Unlike traditional fansubbing, the subtitles they produce are not embedded in the video material but are distributed as .srt files. Thus, the subtitles do not include any type of special formatting and are normally restricted to the bottom of the screen, even if they are superimposed on on-screen texts, such as credits. The non-professional subtitles for U.S. audiovisual products commonly adopt pro-am guidelines. Not requiring embedding nor advanced formatting, they are faster to prepare. Further, since they are plain-text files in .srt format only, they are extremely easy to distribute.

\subsection{Research on non-professional subtitling}

Although some scholars discourage research on non-professional subtitling (Bogucki, 2009; Cornu, 2013), the last decade has seen Translation Studies start paying attention to the nonprofessional sphere of translation. Already in 1999 Nornes was talking about fansubbing as being a form of "abusive subtitling" that was to push the boundaries of mainstream subtitling in the coming years (Nornes, 1999). However, it was not until the middle of the last decade that some scholars became more centered in the products and the communities (Díaz Cintas \& Muñoz Sánchez, 2006; Ferrer Simó, 2005).

Some studies have focused on the comparison of professional and non-professional subtitles, commonly commenting on the low quality of the non-professional subtitles (Bogucki, 2009; La Forgia \& Tonin, 2009; Sajna, 2013). However, with the growth in the number of investigations, other studies have recognized that non-professional subtitles are by definition different from professional ones and that they do not necessarily need to abide by the same professional standards (Feitosa, 2009). Further, researchers have found that non-professional subtitles are not only different but they also relate these differences to the fact that the audiences are different (Barra, 2009; Casarini, 2014; Massidda, 2012). It is likely that people using non-professional subtitles have different needs from the people who watch the TV series on television or DVD.

Research on non-professional subtitling has concentrated on the subtitles, the communities making them and the people interacting in these communities to produce the subtitles. Scholars have explored the social implications of non-professional subtitling both within 
Translation Studies (Pérez-González, 2007, 2013) and neighboring areas (Hemmungs Wirtén, 2012). Nevertheless, we are still ignorant of the other side of the equation: the people using the subtitles. The existing reception studies have tested non-professional subtitling features, but not non-professional subtitles as such. Caffrey (2009) used questionnaires and eye tracking to test the viewer's processing of pop-up glosses in anime, which were included in the official DVD subtitled version. He found that reading pop-up glosses implies increased processing effort and less time allocated to the subtitles, but results in a better understanding of culturally marked items. Künzli and Ehrensberger-Dow (2011) and Ramos Pinto (2013) have carried out experiments on the viewer's reactions and assessment of surtitles as a means to offer additional information related to cultural references in audiovisual products. In both studies, the researchers themselves prepared the surtitles for the material. Their investigations have shown that people are able to cope with additional information on the screen in the form of surtitles. They do not necessarily look at the subtitles for a shorter amount of time in order to make time for the surtitles; viewers rather reduce the amount of time they spend on the rest of the image. Künzli and Ehrensberger-Dow found that "participants' performance in terms of retention of various verbal and visual elements in the movie excerpts was identical in the two conditions" (2011, p. 197).

\section{Methods}

The study reported here is guided by two research questions: 1) does audience reception indicate any difference in comprehension and reactions between the professional and the nonprofessional subtitles? And 2) do better reception scores (in terms of comprehension) correlate positively with professional subtitles?

Reception is operationalized in this study using Gambier's model (2006), which distinguishes between three types of reception (the three Rs): reactions at the cognitive level (gaze data as indicators of attention allocation), responses elicited in terms of the verbal, iconic and narrative attention of the participants as well as their general understanding of the content and their subjective judgment of difficulty and enjoyment of the videos, and repercussions in terms of the users' audiovisual consumption habits and their attitude towards subtitled material. The data were collected using questionnaires, eye tracking and interviews.

The orthodox approach in audiovisual translation mostly assumes higher quality of professional subtitles over non-professional subtitles, with the consequences this entails. Therefore, the initial hypothesis guiding the study is grounded in the fact that non- 
professional subtitling is commonly deemed to be low-quality translation that cannot be compared with professional subtitling (Bogucki, 2009; Dwyer \& Uricaru, 2009; La Forgia $\&$ Tonin, 2009). It assumes that the differences in production conditions between professional and non-professional subtitles will have an effect on the participants' engagement and understanding of the audiovisual content:

- H: Participants' comprehension scores will be higher with professional rather than non-professional subtitles.

A set of sub-hypotheses stemming from this initial hypothesis were postulated to aim at the specific variables. In postulating these sub-hypotheses, as in the initial hypothesis, I was guided by the orthodox view as far as possible and I have included the specific nature of the relation between the variables involved:

- $\quad \mathrm{H}_{1}$ : Reception capacity is higher with professional subtitles.

- $\quad \mathrm{H}_{2}$ : Subtitle-reading effort is lower with professional subtitles.

- $\quad \mathrm{H}_{3}$ : Self-reported comprehension is greater with professional subtitles.

Additionally, I test whether eye-tracking data could offer an explanation for the higher comprehension scores, in case $\mathrm{H}_{3}$ cannot be rejected. Assuming professional subtitles are created following professional standards, I propose the following set of hypotheses:

- $\quad \mathrm{H}_{4}$ : With professional subtitles, more attention is allocated to the image area.

- $\quad$ H5: Mean fixation duration is shorter with professional subtitles.

- $\quad$ H6: Fewer subtitles are skipped when participants are watching professional subtitles.

- $\quad \mathrm{H}_{7}$ : Attention shift varies depending on type of subtitle.

\subsection{Participants}

Fifty-two participants (aged 18-30, mean age 21.19, SD 3.28) were included in the experiments. All participants were students at the Universitat Rovira i Virgili (Tarragona, Spain). The sample was selected taking into account the results of an initial questionnaire that tested audiovisual consumption habits among university students. The questionnaire included an English listening-comprehension test designed for the study. The results allowed me to divide the students into three groups, depending on their level of listening comprehension in English. The participants for this study were 26 students with a low level of English (LLE) and 26 students with a high level of English (HLE). The middling group was excluded. All participants were Spanish or Catalan native speakers. They had a normal or corrected-tonormal vision, by wearing glasses or lenses. The participants were told the project was 
researching the reception of translated products, without any specific reference to subtitling. At the end of the experiment, they were informed about the specific purpose of the study.

The LLE group included 14 women and 12 men, while the HLE group was made up of 21 women and 5 men. Although not desired, this gender imbalance in the HLE group mirrors the situation at the university. Most of the participants in this group came from the B.A. in English in the 2012-2013 academic year, in which 75\% of the students were women. However, no main effect of gender was found in the statistical analysis.

\subsection{Material}

The experiment included three excerpts from the second season of the sitcom The Big Bang Theory. Each excerpt was about three-minutes long. Traditionally, researchers have explored how people react to subtitles when they are totally dependent on them (d'Ydewalle \& Bruycker, 2007; Perego, Del Missier, Porta, \& Mosconi, 2010). They use audiovisual content in a language that is unknown to the research participants. Unlike these studies, I wanted to test how participants react to subtitles under the conditions they are more likely to face. Considering products translated from English are commonly watched by the participants' community and that English is not a totally foreign language for them (Orrego-Carmona, 2014), I opted for a popular TV series that is broadcast in Spain some weeks after its original airdate in the U.S. The time gap between the release in the U.S. and the official broadcast in Spain imply it is likely for the series to be watched with non-professional subtitles by my target audience.

In the study, three sets of subtitles were included: one professional version (PRO) and two non-professional versions (NP1 and NP2). PRO was taken from the DVD distributed in Spain (Warner Bros, 2010). NP1 and NP2 were taken from two online communities: aRGENTeaM (NP1) and TusSeries.com (NP2). These two communities were selected because they follow pro-am guidelines, which makes them comparable to the professional subtitles. A description of aRGENTeaM can be found in Orrego-Carmona (2011) and an account of both communities is included in Pym, Orrego-Carmona, and Torres-Simón (2016). Further, both communities were active in 2008 (when the episodes included in the study were released) and their records indicated that the subtitles were produced by the community - not simply ripped from the DVD versions.

I included two non-professional subtitle versions to account for the variation between nonprofessional subtitling communities. Spanish-language non-professional subtitling 
communities are very clearly divided between those translating into Iberian Spanish (such as TusSeries.com) and those translating into Latin-American Spanish or neutral Spanish (like aRGENTeaM). Users can easily access both, and this could be a factor that sheds some light on the popularity or lack of interest in the subtitles, assuming audiences would be more inclined towards their own version.

\subsection{Procedure}

After completing the initial questionnaire, participants were invited to an individual eyetracking and interview session. The participants were randomly assigned to one of six orders of presentation (

Table 1). I rotated the presentation sequence of the subtitles but not that of the clips. Each participant read each type of subtitle and watched each clip only once. After each clip, the participants answered orally a set of on-screen questions. Once they completed the experiment, they took part in the interview.

Table 1. Presentation sequence used.

\begin{tabular}{llll}
\hline Order & Clip 1 & Clip 2 & Clip 3 \\
\hline Test 1 & NP1 & NP2 & PRO \\
Test 2 & PRO & NP1 & NP2 \\
Test 3 & NP2 & PRO & NP1 \\
Test 4 & NP1 & PRO & NP2 \\
Test 5 & PRO & NP2 & NP1 \\
Test 6 & NP2 & NP1 & PRO \\
\hline
\end{tabular}

The participants' eye movements were recorded using a Tobii X120 eye tracker at $120 \mathrm{hz}$. When operating at $120 \mathrm{~Hz}$, the X120 records eye movement every 8.3 milliseconds and offers an average accuracy of 0.5 degrees. The eye tracker was connected to a 23 " LCD monitor that acted as presentation screen. Participants were seated approximately $60 \mathrm{~cm}$ away from the eye tracker. I calibrated the eye tracker for each participant before the experiment. Lighting was kept relatively constant by closing the blinds and turning on the same lights for all sessions. All of the participants wore over-ear headphones during the session and the volume was maintained at the same level. 


\section{Results and discussion}

The main hypothesis posits that participants' comprehension scores will be higher with professional rather than non-professional subtitles. Bearing in mind the different levels of reception at which subtitles can be compared and contrasted, I formulated seven sub-hypotheses. In the following I address each of these sub-hypotheses and then present a summary for the main hypothesis.

Considering the researchers in Translation Studies have previously advocated the adoption of mixed-effects models (Balling, 2008; Green, Heer, \& Manning, 2013), I resorted to mixedeffect general and linear models to carry out the statistical analyses. I fitted different models using SPSS to put the sub-hypotheses to test. After the model was constructed, pairwise comparisons were carried out to analyze whether the differences between the estimated means of the different levels of the variables were significant. Due to space constraints, the models are not presented here. They can be consulted in Orrego-Carmona (2015).

\section{1. $H_{1}$ : Reception capacity is higher with professional subtitles}

The number of correct answers in a content comprehension test served to assess the participants' reception capacity. Performance was calculated from a set of seven questions asking about verbal, iconic and narrative information (Künzli \& Ehrensberger-Dow, 2011) and gist comprehension.

The Type of subtitle (PRO, NP1, NP2) variable was determined to have a significant main effect on Reception capacity $(\mathrm{F}=5.85 ; \mathrm{p}<0.01)$. Nevertheless, the hypothesis is only partially confirmed. The mean reception capacity with PRO was higher than the mean reception capacity with NP2 (PRO=5.91 vs. NP2=5.37. $\mathrm{t}=-2.857$; $\mathrm{p}<0.01)$; however, it was not significantly higher than NP1, which had a mean of $5.96(\mathrm{t}=-0.22 ; \mathrm{p}=0.82)$.

Reception capacity is a variable composed of a set of variables: Iconic, Narrative and Verbal attention. Among these variables, Type of subtitle has a significant effect on Verbal attention $(\mathrm{F}=9.076 ; \mathrm{p}<0.001)$. The same effect found on Reception capacity is found here too. In $94.8 \%$ of the cases, the participants answered the Verbal attention questions correctly after watching the PRO version. In the case of NP1, they provided the correct answer in $93.6 \%$ of cases. However, with NP2, they answered only $82.6 \%$ of the questions correctly, which is statistically significantly lower than the other two. 
These results are counterintuitive. NP1 was produced by a non-professional Latin-American subtitling community, while NP2 was produced in Spain by a community that uses Iberian Spanish. By reading the subtitles, it is possible to tell the geographical provenance, although the participants did not draw attention to it during the interviews. There are two aspects that can be inferred from these results. 1) Since the results for NP1 and PRO were not significantly different, it is possible to assume that these versions are simply clearer to understand than NP2. 2) Since the PRO version (also localized for the Iberian Spanish market) produced higher scores than NP2, it could be argued that localization in general is not what causes the lower scores. Rather, it could be the case that the NP2 subtitles are somehow less accomplished than the other two and fail to convey the message as effectively.

\section{2. $\mathrm{H}_{2}$ : Subtitle-reading effort is lower with professional subtitles}

The perceived difficulty to follow the subtitles was determined in terms of the participants' self-reported measurements on a 6-point Likert scale ranging from 0 (very difficult) to 5 (very easy). To prevent the participants from focusing excessively on the subtitles, in the phrasing of the question, I used the term translation instead of subtitling. Type of subtitle was not determined to have a significant main effect on Subtitle-reading effort $(F=0.60 ; p=0.55)$. The findings thus do not confirm this hypothesis. However, an interaction effect between Clip and Type of subtitle was identified $(\mathrm{F}=3.10 ; \mathrm{p}<0.05)$.

A pattern similar to the one found in Reception capacity was found for this Subtitle-reading effort. NP1 did not differ significantly from the other two subtitles. When comparing the differences between PRO (4.32) and NP2 (3.57), in Clip 1, the mean score for PRO is 0.75 points higher than the score for NP2 ( $<<0.01)$, but the case is reversed for Clip 3, in which the score for NP2 (4.25) is 0.65 points higher than the score for PRO (3.59). When the clips are taken as reference factor, the best score for NP2 is found in Clip 3, which is approximately 0.6 points higher than the score for NP2 in the other two clips. The only additional significant difference is present in PRO. The score PRO receives in Clip 3 is 0.72 points lower than the score it receives in Clip 1. These results seem to indicate the importance of the audiovisual material in the study. The design of the study aimed to select videos that were comparable. Nevertheless, given the complex nature of audiovisual content, it is understandable that the clips have an effect on the participants' subjective measurements 


\section{3. $\mathrm{H}_{3}$ : Self-reported comprehension is greater with professional subtitles}

The participants were asked to rate their comprehension of the videos, ranging from 0 (no comprehension) to 5 (very good comprehension), right after they had finished watching each clip. The findings from the statistical model do not provide evidence to confirm this hypothesis, since no significant main effect of Type of subtitle on Self-reported comprehension was found $(\mathrm{F}=1.54 ; \mathrm{p}=0.21)$.

Similarly to Subtitle-reading effort, there was a significant effect of the interaction between Clip and Type of subtitle $(\mathrm{F}=2.92 ; \mathrm{p}<0.05)$. However, the results scarcely follow an identifiable pattern: There are two pairwise comparisons that show significant differences and both of them involve NP2. In Clip 2, there is a significant difference between NP2 and PRO $(\mathrm{t}=-2.31 ; \mathrm{p}<0.05)$, with the PRO version receiving 0.5 more points on average than NP2. On the contrary, in Clip 3, the ratings for NP2 are 0.57 points higher than those for NP1 $(\mathrm{t}=-2.67$; $\mathrm{p}<0.01)$.

It could be assumed that the type of subtitle did not influence the participants' rating for their self-reported comprehension. Other factors, such as their reported enjoyment, use of subtitles and, intuitively, prior knowledge of the clips were determined to be significant effects of Selfreported comprehension. However, self-reported measurements are known to be troublesome in reception studies due to the possibility that participants overestimate (Antonini, 2005, 2008; Bucaria \& Chiaro, 2007) or underestimate (Caffrey, 2009) their understanding of the audiovisual translated content.

\section{4. $\mathrm{H}_{4}$ : With professional subtitles, more attention is allocated to the image area}

Attention allocation refers to the distribution of cognitive resources among the different areas on the screen, in this case, the image and the subtitle. Following Künzli and EhrensbergerDow (2011), two relative measurements are used for this variable: the fixation duration and the number of fixations. When watching subtitled audiovisual products, subtitles have to compete for the attention against the other sources of information available. Both the acoustic and visual channels can offer verbal and non-verbal information; like those two channels, the subtitles also demand a share of the cognitive resources from viewers. The amount of attention that viewers have to allocate to the subtitles in relation to the other sources of information is considered an indicator of the cognitive effort they entail. Whenever some subtitles demand more time or require a higher number of fixations than others, it can be 
assumed that those subtitles are more cognitively demanding (Kruger, Szarkowska, \& Krejtz, 2015)

In the case of the number of fixations, attention allocation was calculated as the percent ratio between the total number of fixations on an area of interest and the total number of fixations in the recording. Attention allocation in terms of fixation duration (ms) was calculated as the percent ratio between the total time spent on a given area of interest and the total gaze time in the recording. I used the percentage of fixations and the percentage of the duration of fixations as standardization methods for running the analysis, considering the different lengths of the video excerpts. This means that each variable for the subtitle area of interest is complementary to its corresponding equivalent for the image area. The analysis presented here offers the results for Percentage of fixations on the subtitle area and not the results of the model for the variable Percentage of fixations on the image area, to avoid redundant information.

Based on the eye-tracking data, this hypothesis cannot be confirmed. The Percentage of fixations on the subtitle area was not significantly shorter for the professional subtitles. In the HLE group, the mean percentage of fixations on the subtitle area was $46 \%$ for PRO, $43 \%$ for NP1 and 44\% for NP2. Among LLE participants, the mean percentage of fixations on the subtitle area for PRO was $61 \%$, while the NP1 and the NP2 had means of $62 \%$ and $64 \%$, respectively.

\section{5. $H_{5}$ : Mean fixation duration is shorter with professional subtitles}

The mean fixation duration is computed for the subtitle area and the image area independently by adding up the duration of all fixations on the area and dividing the result by the number of fixations on the area. The hypothesis stated that the professional subtitles would have shorter mean fixations than the non-professional subtitles. This hypothesis is confirmed. The main effect of Type of subtitle $(\mathrm{F}=26.97 ; \mathrm{p}<0.001)$ and the interaction between Clip and Type of subtitle $(\mathrm{F}=5.83 ; \mathrm{p}<0.01)$ are significant for Mean fixation duration on the subtitle area. Additionally, Type of subtitle was found to have a significant main effect on Mean fixation duration on the image area $(\mathrm{F}=5.52 ; \mathrm{p}<0.01)$.

The results indicate that the mean on the PRO version $(178.41 \mathrm{~ms})$ is significantly shorter than the mean fixations on both NP1 and NP2 subtitles (196.69 ms and 201.84 ms). Mean fixation duration is commonly regarded as an indicator of cognitive effort (d'Ydewalle \& Bruycker, 2007; Kruger et al., 2015; Perego et al., 2010). Rayner and Pollatsek (2006) 
argue that reading studies have provided solid evidence to accept that longer fixations on words are associated with higher difficulty to understand them.

The mean fixation duration estimated with the effect of Type of subtitle concords with the mean fixation duration on subtitles reported by d'Ydewalle and Bruycker (2007) for adult viewers watching subtitled material: $178 \mathrm{~ms}$ for one liners and $179 \mathrm{~ms}$ for two liners. Kruger et al. (2015) reported a mean fixation of $186.55 \mathrm{~ms}$ among hearing viewers watching subtitles presented at a speed of 12 characters per second, which is a faster speed than the speed of any of the subtitles included in this study. Interestingly enough, the mean fixations reported in other studies are still longer than the means I found for the non-professional subtitles. The mean fixation reported by Caffrey (2009, p. 163) is $237 \mathrm{~ms}$ for one liners and $201.43 \mathrm{~ms}$ for two liners. Perego et al. (2010, p. 259) found a 221-ms mean fixation while Künzli and Ehrensberger-Dow (2011) reported a mean of 0.36 seconds. Among the studies above, only d'Ydewalle and Bruycker (2007) and Künzli and Ehrensberger-Dow (2011) include participants who are supposed to be used to subtitling, since this is the most widely used audiovisual translation modality in Flemish-speaking Belgium and German-speaking Switzerland (Media Consulting Group, 2011). Perego et al. (2010) present an experiment carried out in Italy, primarily a dubbing country, so their results should be more similar to mine. Although the mean fixations on the non-professional versions in my study are very similar to theirs, the mean fixation in PRO is shorter.

However, the results of the mean fixations presented here should be taken with caution. Although it is hard to test if this is to some extent caused by the layout of the subtitles on the screen, it is worth commenting that the two non-professional versions have the same layout while the professional version is different. All three sets of subtitles where white, but the PRO subtitles had a slightly larger font and were not as bright as the non-professionals. This difference emerged as a result of the focus on ecological validity that was put on the experiment and was not anticipated in the design. It is possible that this had an effect on the viewer's reactions, but confirming this would require additional studies. The layout of the subtitles constitutes an almost unexplored field of research, with some exceptions in the field of creative subtitling (Fox, 2016; McClarty, 2014).

A more detailed analysis of the mean fixations can be based on the interaction between Type of subtitle and Clip. It shows that PRO differs significantly from the other types of subtitles only in the first two clips and not in the third. This could indicate that participants become used to the subtitles over time or their behavior stabilizes as a result of immersion in the 
whole viewing experience. However, it could also be a clip-influenced effect. With only three three-minute clips in this experiment, it is impossible to test this any further.

Type of subtitle also influenced the mean fixation on the image area. Again, the shortest mean fixation was found in PRO (333.55 ms), which is significantly different from the mean for NP1, $357 \mathrm{~ms}$. NP2 had an estimated mean fixation of $346.59 \mathrm{~ms}$ and is not significantly different from any of the other two means. The fact that subtitles affect the viewing process as a whole has already been shown in previous research: Bairstow (2011) found that for the participants who relied on the subtitles (monolingual participants who did not understand the original language), the subtitles acted as a facilitating factor for the understanding of visual information. Instead of obtaining lower scores on the visual attention questions due to the amount of time dedicated to the subtitle area, the participants who relied on the subtitles obtained higher scores on visual information perception than the bilingual participants who were assumed to focus more on the image (Bairstow, 2011).

\subsection{H6: $_{6}$ Fewer subtitles are skipped when participants are watching professional subtitles}

The percentage of skipped subtitles was calculated by counting the number of unfixated subtitles (subtitles without a single fixation) and dividing this figure by the total number of subtitles in the clip. This is an indicator of the participants' dependence on the subtitles as a source of information. Subtitle speed imposes a cognitive demand on viewers: If the subtitles are too fast, it is more likely that more subtitles will not be fixated upon. The results did not provide any evidence to confirm this hypothesis. No significant effect for Type of subtitle $(\mathrm{F}=2.49 ; \mathrm{p}=0.087)$ was found on Skipped subtitles. The subtitles included in this study did not vary much in terms of subtitle speed: the PRO version had an average speed of 10.7 characters per second, while the NP1 and NP2 version are presented at 10.1 and 10.9 characters per second on average.

\section{7. $\mathrm{H}_{7}$ : Attention shift varies depending on type of subtitle}

Attention shifts are the constant changes of focus from the image to the subtitles and vice versa. In a linear reading behavior, each subtitle should cause two attention shifts: one shift from the image to the subtitle area and another one from the subtitle area to the image. The attention shift ratio indicates the number of times the viewer's gaze alternates between the two areas per subtitle. Type of subtitle was found to produce a significant effect on Attention 
shift ratio $(\mathrm{F}=7.32 ; \mathrm{p}<0.01)$. The attention shift ratio for PRO was 2.01 and was significantly higher than for the others, 1.88 for NP1 and 1.81 for NP2.

Kruger et al. claim that "the fewer the gaze shifts, the more fluent the reading and vice versa" (2015, pp. n.p.). However, this is not necessarily the only possibility: Assuming subtitles provide viewers with the time necessary to read the subtitle and check the image, there should always be a minimum number of attention shifts: two shifts per subtitle. A higher ratio could indicate re-reading, which is normally taken as a sign of greater difficulty in reading (Krejtz, Szarkowska, \& Krejtz, 2013), and lower scores could imply skipped subtitles.

The Code of Good Subtitling Practice (Carroll \& Ivarsson, 1998) states that a minimum of four frames should be left between back-to-back subtitles to allow the eyes of the viewer to recognize there is a new subtitle on the screen, thus preventing the flash effect. In the PRO subtitles used in this experiment, the minimum time left between two given subtitles was 160 ms. However, this rule was not used in the non-professional subtitles included in this study. For instance, the median for the time between two subtitles was found to be as short as $20 \mathrm{~ms}$ for NP1 in Clip 2, including many instances of only $10 \mathrm{~ms}$ between subtitles. This indicates these subtitles virtually overlap to the human eye. As evidenced by the data, viewers mostly become aware of the change and read the overlapping subtitles without going back to the image, thus reducing the number of shifts but causing them to remain on the subtitle area for longer periods of time. Thus, even if the number of attention shifts is low, the spotting is disturbing the process of simultaneously checking the image and the subtitles. In this scenario, it could be said that the PRO version, with an average attention shift ratio of 2.01, motivates a more consistent behavior in which participants start reading the subtitles and "glance at the video action after they finish reading" (Jensema, el Sharkawy, Danturthi, Burch, \& Hsu, 2000, p. 284).

\subsection{Conclusion on the main hypothesis}

As can be seen, the data do not provide enough evidence to confirm the main hypothesis. Only two of the seven postulated sub-hypotheses are confirmed: 1) The PRO version resulted in shorter Mean fixation duration on both the subtitle and the image areas, and 2) the ratio of Attention shifts varied depending on the subtitles. In fact, the attention shift ratio indicates that, on average, professional subtitles allow participants to have a more consistent reading behavior. The other eye-tracking measurements, Attention allocation and Skipped subtitles, did not show that the reception scores were higher for the professionals. Further, the self- 
reported measurements related to Subtitle-reading effort and Comprehension did not have a significant effect of Type of subtitle. Perhaps the most surprising finding is that Reception capacity was affected by Type of subtitle but only the Iberian Spanish version was significantly different from the professional version. The Latin-American version, in neutral Spanish, obtained results that are not significantly different from the professional version.

\section{Conclusions}

Translation Studies can no longer consider non-professional subtitling as an outcast of the translation panorama. People around the world, probably mainly the young, are becoming more and more used to these subtitles and the communities producing them seem to be getting better at what they do. Although there is variation in the non-professional subtitling spectrum, from a reception perspective, it is possible to say that there are non-professional translations that are as good as their professional counterparts. This clearly raises some issues that need to be attended to: how do these communities evolve in such a way that they produce subtitles similar to professional subtitles? What can translator trainers adopt or adapt from these communities in order to help to develop translator competence?

Interestingly, the participants in this study were not more inclined towards the Iberian nonprofessional subtitles and did not even recognize the difference between the Latin-American and Iberian subtitles. In a context where the distribution of subtitles is a global phenomenon and localization is seen as a must for many companies, this clearly constitutes an issue that could be addressed in future studies: to what extent is localization effective and how reluctant are the audiences when they are faced with products in other linguistic varieties? It is possible that there is a higher degree of acceptance due to exposition to foreign products; in the same way that users seem to use different standards for professional and non-professional subtitles, it is likely they are also becoming more used to assessing each product under its own conditions.

From a methodological point of view, this study has shown that reception studies using eye tracking and questionnaires are sound methods to put subtitling guidelines to test. For instance, the results have shown that allowing time between subtitles grants viewers the opportunity to have a more systematic reading process, by providing them with enough time to read the subtitles and constantly check the image. Conclusions supported with empirical data could help subtitlers decide among a multiplicity of options and revise traditionally accepted subtitling guidelines. 
Some limitations have to be considered. These results should be taken with caution given that the exposure to each type of subtitle was rather short. Longer clips would probably produce different results, but the technical inconveniences make it almost impossible at this point to carry out longer eye-tracking studies with a large number of participants - Kruger and Steyn (2014) use longer clips with 36 participants but comment on the technical issues and timeconsuming activity of processing such a large amount of data. Additionally, other types of non-professional subtitles could produce more rejection. Further, from where we as researchers stand right now, it is becoming more necessary to address the legal issues relevant to non-professional subtitling. Non-professionalism is pushing the boundaries of translation and extending its social dimension, whether we like it or not, so we need to assess how this is framed within the legal systems involved. The discussion related to the opposition of professional and non-professional translation, from a Translation Studies perspective, should not stay at the level of what is better or worse, but rather look forward and focus on the possibilities offered by this newly acquired knowledge. 


\section{References}

Antonini, R. (2005). The perception of subtitled humor in Italy. Humor - International Journal of Humor Research, 18(2), 209-225. doi:10.1515/humr.2005.18.2.209

Antonini, R. (2008). The perception of dubbese: An Italian study. In D. Chiaro, C. Heiss, \& C. Bucaria (Eds.), Between Text and Image. Updating Research in Screen Translation (pp. 135-148). Amsterdam and Philadelphia: John Benjamins Publishing Company.

Bairstow, D. (2011). Audiovisual Processing while Watching Subtitled Films: A Cognitive Approach. In A. Şerban, A. Matamala, \& J.-M. Lavaur (Eds.), Audiovisual translation in close-up: Practical and theoretical approaches (pp. 205-219). Bern: Peter Lang.

Balling, L. W. (2008). A brief introduction to regression designs and mixed-effects modelling by a recent convert. In S. Göpferich, A. L. Jakobsen, \& I. M. Mees (Eds.), Copenhagen Studies in Language 36. Looking at Eyes: Eye-tracking studies of reading and translation processing (pp. 175-192). Frederiksberg: Samfundslitteratur.

Barra, L. (2009). The mediation is the message: Italian regionalization of US TV series as cocreational work. International Journal of Cultural Studies, 12(5), 509-525. doi:10.1177/1367877909337859

Bogucki, Ł. (2009). Amateur subtitling on the Internet. In J. Díaz Cintas \& G. Anderman (Eds.), Audiovisual translation. Language transfer on screen (pp. 49-57). Basingstoke: Palgrave Macmillan.

Bucaria, C., \& Chiaro, D. (2007). End user perception of screen translation: The case of Italian dubbing. Tradterm, 13(1), 91-118.

Caffrey, C. (2009). Relevant abuse? Investigating the effects of an abusive subtitling procedure on the perception of TV anime using eye tracker and questionnaire (Unpublished $\mathrm{PhD}$ thesis). Dublin City University, Dublin. Retrieved from http://doras.dcu.ie/14835/1/Colm_PhDCorrections.pdf

Carroll, M. \& Ivarsson, J. (1998). Code of good subtitling practice.

Casarini, A. (2014). The perception of American adolescent culture through the dubbing and fansubbing of a selection of US teen series from 1990 to 2013 ( $\mathrm{PhD}$ thesis). Università di Bologna, Forlì.

Cornu, J.-F. (2013). De Barcelone aux bords du Rhin : le doublage et le sous-titrage au fil des congrès. L'écran traduit, 2((automne 2013)), 107-122. Retrieved from http://ataa.fr/revue/archives/2162

d'Ydewalle, G., \& Bruycker, W. de. (2007). Eye movements of children and adults while reading television subtitles. European Psychologist, 12(3), 196-205. doi:10.1027/1016-9040.12.3.196

Díaz Cintas, J., \& Muñoz Sánchez, P. (2006). Fansubs: Audiovisual translation in an amateur environment. JoSTrans, The Journal of Specialised Translation, 6, 37-52. Retrieved from http://www.jostrans.org/issue06/art_diaz_munoz.php

Dwyer, T. (2012). Fansub dreaming on ViKi. The Translator, 18(2), 217-243. doi:10.1080/13556509.2012.10799509

Dwyer, T., \& Uricaru, I. (2009). Slashings and subtitles: Romanian media piracy, censorship, and translation. The velvet light trap, 63(1), 45-57. doi:10.1353/vlt.0.0026

Feitosa, M. P. (2009). Legendagem comercial e legendagem pirata: um estudo comparado (Postgraduate thesis). Faculdade de Letras da UFMG, Minas Gerais.

Fernández Costales, A. (2012). Collaborative Translation Revisited: Exploring the Rationale and the Motivation for Volunteer Translation. Forum, 10(1), 115-142. 
Fernández Costales, A. (2013). Crowdsourcing and collaborative translation: mass phenomena or silent threat to Translation Studies? Hermēneus, 15, 85-110.

Ferrer Simó, M. R. (2005). Fansubs y scanlations: la influencia del aficionado en los criterios profesionales. Puentes, 5, 27-44. Retrieved from http://www.ugr.es/ greti/puentes/puentes6/04\%20Maria\%20Rosario\%20Ferrer.pdf

Fox, W. (2016). Integrated Titles - An Improved Viewing Experience?: A Comparative Eye Tracking Study on Pablo Romero Fresco's Joining the Dots. In S. Hansen-Schirra \& S. Grucza (Eds.), Eyetracking and Applied Linguistics (pp. 5-30). Berlin: Language Science Press.

Gambier, Y. (2006). Multimodality and audiovisual translation. In M. Carroll, H. GerzymischArbogast, \& S. Nauert (Eds.), Audiovisual Translation Scenarios. Retrieved from http://euroconferences.info/proceedings/2006_Proceedings/2006_Gambier_Yves.pdf

Green, S., Heer, J., \& Manning, C. D. (2013). The efficacy of human post-editing for language translation. In CHI 2013: Changing Perspectives (pp. 439-448). Paris.

Hemmungs Wirtén, E. (2012). Swedish subtitling strike called off! Fan-to-fan piracy, translation, and the primacy of authorisation. In D. Hunter, R. Lobato, M. Richardson, \& J. Thomas (Eds.), Amateur Media: Social, Cultural and Legal Perspectives (pp. 125-136). London, New York: Routledge.

Jääskeläinen, R. (2010). Are all professionals experts? In G. M. Shreve \& E. Angelone (Eds.), American Translators Association Scholarly Monograph Series. Translation and Cognition (XV, pp. 213-227). Amsterdam and Philadelphia: John Benjamins Publishing Company. doi:10.1075/ata.xv.12jaa

Jensema, C. J., el Sharkawy, S., Danturthi, R. S., Burch, R., \& Hsu, D. (2000). Eye movement patterns of captioned television viewers. American Annals of the Deaf, 145(3), 275-285.

Krejtz, I., Szarkowska, A., \& Krejtz, K. (2013). The effects of shot changes on eye movements in subtitling. Journal of Eye Movement Research, 6(5), 1-12.

Kruger, J.-L., \& Steyn, F. (2014). Subtitles and eye tracking: Reading and performance. Reading Research Quarterly, 49(1), 105-120.

Kruger, J.-L., Szarkowska, A., \& Krejtz, I. (2015). Subtitles on the moving image: An overview of eye tracking studies. Refractory: a Journal of Entertainment Media, 25, np. Retrieved from http://refractory.unimelb.edu.au/2015/02/07/kruger-szarkowska-krejtz/

Künzli, A., \& Ehrensberger-Dow, M. (2011). Innovative subtitling: A reception study. In C. Alvstad, A. Hild, \& E. Tiselius (Eds.), Methods and Strategies of Process Research: Integrative Approaches in Translation Studies (pp. 187-200). Amsterdam and Philadelphia: John Benjamins Publishing Company.

La Forgia, F., \& Tonin, R. (2009). In un tranquillo week-end di paura, un Esorcista volò sul nido del...: Un case study sui rimandi intertestuali nel sottotitolaggio e doppiaggio italiano e spagnolo della serieSupernatural. inTRAlinea, 11, n.p. Retrieved from http://www.intralinea.org/archive/article/In_un_tranquillo_week-end_di_paura_un_Esorcista

Leadbeater, C., \& Miller, P. (2004). The pro-am revolution: How enthusiasts are changing our society and economy. London: Demos.

Massidda, S. (2012). The Italian fansubbing phenomenon (PhD Thesis). Università degli Studi di Sassari, Italy.

McClarty, R. (2014). In support of creative subtitling: contemporary context and theoretical framework. Perspectives, 22(4), 592-606. doi:10.1080/0907676X.2013.842258

Media Consulting Group. (2011). Study on the use of subtitling: The potential of subtitling to encourage foreign language learning and improve the mastery of foreign languages 
EACEA/2009/01. Final Report. Retrieved from

http://www.mcu.es/cine/docs/Novedades/Study_on_use_subtitling.pdf

Nornes, A. M. (1999). For an abusive subtitling. Film Quaterly, 52(3), 17-34.

O'Hagan, M. (2011). Community translation: Translation as a social activity and its possible consequences in the advent of Web 2.0 and beyond. Linguistica Antverpiensia, 10, 11-23. Retrieved from http://www.lans-tts.be/docs/lans10-2011-intro.pdf

Orrego-Carmona, D. (2011). The empirical study of non-professional subtitling: A descriptive approach (Master's minor dissertation). Universitat Rovira i Virgili, Tarragona.

Orrego-Carmona, D. (2014). Subtitling, video consumption and viewers: The impact of the young audience. Translation Spaces, 3, 51-70. doi:10.1075/ts.3.03orr

Orrego-Carmona, D. (2015). The reception of (non)professional subtitling (Unpublished $\mathrm{PhD}$ thesis). Universitat Rovira i Virgili, Tarragona.

Perego, E., Del Missier, F., Porta, M., \& Mosconi, M. (2010). The Cognitive Effectiveness of Subtitle Processing. Media Psychology, 13, 243-272. doi:10.1080/15213269.2010.502873

Pérez-González, L. (2007). Intervention in new amateur subtitling cultures: a multimodal account. Linguistica Antverpiensia, 7, 67-80.

Pérez-González, L. (2013). Amateur subtitling as immaterial labour in digital media culture: An emerging paradigm of civic engagement. Convergence: The International Journal of Research into New Media Technologies, 19(2), 157-175. doi:10.1177/1354856512466381

Pym, A. (2012). On translator ethics: Principles for mediation between cultures. Amsterdam and Philadelphia: John Benjamins Publishing Company.

Pym, A. (2014). Translator associations — from gatekeepers to communities. Target, 26(3), 466-491. doi:10.1075/target.26.3.06pym

Pym, A., Orrego-Carmona, D., \& Torres-Simón, E. (2016). Status and technology in the professionalization of translators. Market disorder and the return of hierarchy. JoSTrans, The Journal of Specialised Translation. (25), 33-53. Retrieved from http://www.jostrans.org/issue25/art_pym.php

Ramos Pinto, S. (2013). How accessible are audiovisual products: A reception study of subtitled film. Paper presented to the 5th International Conference Media for All: Audiovisual Translation, Expanding Borders. Dubrovnik.

Rayner, K., \& Pollatsek, A. (2006). Eye-movement control in reading. In M. J. Traxler \& M. A. Gernsbacher (Eds.), Handbook of Psycholinguistics (2nd ed., pp. 613-658). Amsterdam and Boston: Elsevier/Academic Press.

Sajna, M. (2013). Amateur subtitling - selected problems and solutions. T21N - Translation in Transition, 3, 1-18. Retrieved from http://www.t21n.com/homepage/articles/T21N-2013-03Sajna.pdf

Tapscott, D., \& Williams, A. D. (2006). Wikinomics: How Mass Collaboration Changes Everything. New York: Portfolio.

Warner Bros, c. (Director). (2010). The Big Bang Theory. Created by Chuck Lorre and Bill Prady. Madrid. 